\title{
Evaluation of the effect of alcoholic extract of some plants on Culicinae mosquito larvae and survey of mosquito species and their natural enemies
}

Muqdad Ali Abdullah ${ }^{1}$, Sawsan Ahmed Khalaf Elhadeeti ${ }^{1}$, Mohamed Ahmed Ibrahim Ahmed ${ }^{2}$

${ }^{1}$ Department of Plant Protection, College of Agricultural Engineering Sciences, University of Baghdad, Baghdad 10071, Iraq

${ }^{2}$ Plant Protection Department, Faculty of Agriculture, Assiut University, Assiut 71526, Egypt

\begin{abstract}
The study was conducted at the University of Baghdad (Aljadiria) by taking samples from three sites (water environments) per week, which are the stagnant water environment (Site A), the water table (Site B) and the water basin (Site C) for the purpose of studying the population density of mosquitoes and their accompanying predators. The results showed that the population density of mosquito larvae was the highest in the stagnant water environment (Site A), followed by the water table (Site B), and then the water basin (Site C). As for predators, the results indicated that small water bugs were more present in site A and in large numbers, followed by small tremors, then Gambusia fish, while large tremors and large water bugs were relatively few. It was found that using clove extract (Syzygium aromaticum) reduced mosquito larvae by $100 \%$, at highest concentrations 10 and $15 \%$, the mortality was $100 \%$ after 2 hours. Plus, it was found that apple of sodom extract (Calotrpis procera) affected the second and fourth instars less than cloves extract. The lantana extract (Lantana camara) was the least effective extract against mosquito larvae.
\end{abstract}

Keywords: Mosquitoes, Predators, Plant extract, Clove, Apple of Sodom, Lantana 


\section{Introduction}

Mosquitoes are a known as a serious vector of numerous diseases in the world, including the pathogens responsible for viral encephalitis, malaria, yellow fever, dengue fever and elephantiasis ( Shaalan and Canyon, 2009; Brathwaite, 2012 ; Ahmed and Vogel 2020). However, mosquito-borne diseases remain a major problem in most tropical and subtropical countries ( El-Hadeeti et al., 2017 ) .

The resistance of mosquitoes to pesticides and the non-selection of these pesticides have led to the emergence of many problems in the struggle with mosquitoes as a vector for human diseases (Ahmed and Othman 2020; Ahmed and Vogel 2020). These problems can be faced through integrated management strategies. There were alternative methods and strategies to reduce mosquitoes, including biological control in order to avoid the use of pesticides that have control, such as plant extracts, act as pesticides to kill larvae, inhibit the growth of insects, or as repellents and inhibitors to laying eggs ( Mittal. and Subbarao. 2003; Achee et. al. 2019 ), These herbal products that act as natural insecticides have been found to have extracts from different parts of different plants and materials have mosquito larvicidal and repellent activity (Sharma et al. 1998; Sosan et al. 2001). Several recent studies have indicated that phytochemicals play a major role in the mosquito control program (WHO 1970; El Hag et al. 1999).

The recent increase in the use of predators, including insects (Mogi 2007) has increased in order to provide a suitable timing for chemical treatments to avoid harm to the existing natural determinants and to provide an appropriate environment for biological control and environmental treatment, as a method that provides detailed knowledge of the environment of these insects and their natural enemies (De Bueno et. al. 2017)

The presence of predators is important within temporary pond communities to control mosquito populations (Elono et. al. 2010) . Many species of bugs from the family Notonectidae and Libllulidae have proven their efficiency on mosquitoes. Diagnosing and monitoring mosquito larvae and their predators in ponds and 
streams are among the control measures in the field of biological control and observing the population density of insects (predators) in conjunction with the difference in population density of mosquito species in addition to invertebrates that are predators to mosquitoes (Hasty and Yang, 2011). The study aims to some test plant extracts in controlling mosquito larvae as alternatives to pesticides and to diagnose the types of mosquitoes and their accompanying vital enemies in the vicinity of the University of Baghdad (Aljadiria) by conducting a random survey in the area, taking samples from ponds and streams, and then estimating their population density and determining the relationship between them.

\section{Materials and Methods}

\section{Determining randomly located locations:}

Three sites were randomly selected for sampling from the water table located in the vicinity of the University of Baghdad. Where the presence of stagnant and running water was detected, the water surface is examined with the naked eye to ensure the presence of mosquitoes, and three sites were identified for sampling.

\section{The method of sampling and the materials used in it.}

Samples were taken weekly using a ladle (a plunger), which is a $1000 \mathrm{ml}$ metal container connected to a 1-meter-long wooden handle, the ladle is dipped in water (at each of the specified sites) 10 times and at different depths to take the sample, the sample taken was placed in each dive contented water and aquatic organisms and emptied into a piece of cloth (micro-openings to prevent passage of smallsized organisms). It allowed the passage of water and the aquatic organisms that are collected in a large plastic container of 20 liters' capacity and 10 liters of water are added to it, the container in which the total of aquatic organisms was taken to the laboratory.

\section{Sorting and diagnosing aquatic organisms:}

\section{Sorting aquatic organisms:}


After bringing the containers containing aquatic organisms to the laboratory, the organisms were sorted by emptying the water and passing it through a piece of thin-hole cloth to isolate the different aquatic organisms for all their life stages.

Diagnosis of the types of mosquitoes present in the sample, as well as other types of insects, by specialists in the classification of insects in the Department of Plant Protection / College of Agriculture / University of Baghdad, as for other aquatic organisms, they were diagnosed by specialists in animal science in this section, as for the types that cannot be diagnosed in Plant Protection Department, it was sent to the Natural History Museum in Bab Al-Moazam for diagnosis.

\section{Estimating the population density of mosquito species and other aquatic organisms:}

The population density of mosquito species and aquatic organisms was calculated after its diagnosis by referring to the specialists in this field, where the members of aquatic organisms from mosquitoes and others were calculated along the dates of sample collection, and then a closure was placed between the population density of mosquito species and the population density of aquatic organisms that associated with the mosquitoes to determine the relationship the density of mosquitoes during the period of study and the effect of the numbers and types of aquatic organisms that present with them on the size of their density. Subsequently, the possibility of recommending aquaculture that was supposed to be an effect on the population of mosquitoes and testing their effect individually or in conjunction with the rest of the aquatic organisms in reducing the population of mosquitoes.

\section{Collecting and breeding mosquitoes:}

The method of the World Health Organization (WHO) (1970) was followed in raising mosquitoes, where it was collected from a sewage channel in a random residential house in one of the course areas in Baghdad and the mosquitoes were diagnosed by specialists from the professors of the Prevention Department, College of Agricultural Engineering Sciences

\section{Collecting and preparing plant samples:}

Collecting samples of apple of Sodom (C. procera) plant and lantana (L. camara) grown near the Faculty of Agricultural Engineering Sciences. The leaves are 
collected, washed with tap water, left to dry, and then ground with an electric grinder then it was filtered using a sieve with a hole size of 50 mesh to obtain a ready-made powder. The cloves ( $S$. aromaticum) plant was brought from the local market. It was ground with an electric grinder and then the powder is filtered using a sieve with a hole size of 50 mesh.

\section{Preparation of aqueous extract of plants:}

Fifty grams of powder from each plant and put it in $1000 \mathrm{ml}$ glass beaker, then add $200 \mathrm{ml}$ distilled water to it and were put it in the electric vibrator for 24 hours, then the solution was filtered with filter paper, then the solution was concentrated in the rotary evaporator and the aqueous extract is collected for each plant and placed in shaded glass bottles and placed in the refrigerator until testing.

Concentrations of $2.5,5,10$, and $15 \%$ of each plant extract were prepared for the treatments. $100 \mathrm{ml}$ of table water were put into a $500 \mathrm{ml}$ plastic container and then release 20 larvae from each of the second and fourth instar, with a biscuit and yeast at the rate of 1: 2 , then $5 \mathrm{ml}$ of each concentration was added with three replications for each of the concentrations of each plant, in addition to the comparison treatment that is made by adding $5 \mathrm{ml}$ of tap water and with three replications. Readings were taken after 2, 4, 6, 24, and 48 hours, and this was done by recording the number of dead larvae in each treatment.

\section{Results and Discussions}

\section{Population density of mosquitoes and their accompanying predators:}

The results in Table (1) indicated that the numerical density of mosquito larvae was higher in the pond (Site A) than in the rest of the sites, which are the water table (Site B) and the water basin (Site C), as the average number of larvae collected during the study period was 22.53 , in site A, the number of larvae was 2.46 in site $B$, while in site $C$, the number reached 1.86 . The highest number of larvae in site A reached 65 on 4/5/2018, while no one was noticed. At the same site on 10/26/2017, and in Site B, the mosquito larvae reached their highest numerical 
density on $2 / 27 / 2018$. The number of larvae was 8 , while no larvae were noticed at the period from 12/14/2017 to 17/17. 1/2018 in addition to the date 4/16/2018, as he also did not notice the presence of mosquito larvae, and in Site $\mathrm{C}$, the highest number of larvae was reached on $3 / 12 / 2018$, while the presence of mosquito larvae was not observed on the dates 10/26, 14/12 - 12/27/2017 and 3/8/2018, respectively. These results can be attributed to mosquitoes' preference for stagnant water environment more than running or moving water because the stagnant water environment provides them with suitable organic matter available for their livelihood, growth, reproduction and development. As for the presence of mosquito predators, it is noted from the same table that the number of predators was higher in site $\mathrm{C}$, with an average of 3.06 predators, followed by site $\mathrm{A}$, the number of predators was 2.4 predators, while the number did not exceed 0.86 predators in site $\mathrm{C}$, and this indicates that there is a somewhat positive relationship, among mosquito larvae and their predators. Despite the decrease in the numbers of mosquito larvae or their disappearance in some periods as a result of weather conditions that are not suitable for their living, but they were generally present throughout the study period, which means that they are present throughout the months of the year and this explains their spread around the World (Abu Al-Hab, 1990).

\section{Types of predators accompanying mosquitoes:}

The results in Table (2) show that the Corixidae family of small water bugs were present in large numbers (more than 20 individuals) in site $\mathrm{A}$ and then in medium numbers at site $\mathrm{C}$.

With smaller numbers in site $\mathrm{B}$, it is followed in terms of numerical density by the small dependent tremor that belongs to the family Coenagrinidae, which was present in high numbers (10-20 individuals) in site $\mathrm{C}$ and in small numbers in site $\mathrm{B}$ and was not present in site A, then the Gambusia fish was present in numbers Medium in site $\mathrm{C}$, the large water bug and large water bugs were in small numbers (large water bugs were collected from site $\mathrm{C}$, large tremors were collected from site B). El-Hadeeti et al. (2017) referred that the Gambusia fish is one of the biological control elements of Culex pipiens larvae.

Table 1. No. of mosquito larvae and their associated predators in study locations 
INTERNATIONAL JOURNAL OF

FAMILY STUDIES, FOOD SCIENCE AND NUTRITION

HEALTH

\begin{tabular}{|c|c|c|c|c|c|c|}
\hline \multirow{2}{*}{$\begin{array}{l}\text { Sampling } \\
\text { Date }\end{array}$} & \multicolumn{2}{|l|}{ (A) Pond } & \multicolumn{2}{|c|}{ (B) Streamlet } & \multicolumn{2}{|l|}{ (C) Pool } \\
\hline & $\begin{array}{l}\text { Mosquito } \\
\text { Larvae } \\
\text { No. }\end{array}$ & \begin{tabular}{|l|} 
No. of \\
Predators
\end{tabular} & $\begin{array}{l}\text { Mosquito } \\
\text { Larvae } \\
\text { No. }\end{array}$ & \begin{tabular}{|l|} 
No. of \\
Predators
\end{tabular} & $\begin{array}{l}\text { Mosquito } \\
\text { Larvae } \\
\text { No. } \\
\end{array}$ & $\begin{array}{ll}\text { No. } & \text { of } \\
\text { Predators }\end{array}$ \\
\hline $26 / 10 / 2017$ & - & - & 5 & 1 & - & - \\
\hline 23/11/2017 & 2 & 14 & 2 & 1 & 3 & - \\
\hline 14/12/2017 & 8 & 1 & - & - & - & 1 \\
\hline 20/12/2017 & 17 & - & - & - & - & - \\
\hline 27/12/2017 & 6 & - & - & - & - & - \\
\hline $11 / 1 / 2018$ & 10 & - & - & - & 2 & - \\
\hline $17 / 1 / 2018$ & 4 & - & - & - & 1 & - \\
\hline $24 / 1 / 2018$ & 3 & - & 5 & - & 4 & 4 \\
\hline $28 / 1 / 2018$ & 10 & - & 3 & - & 2 & 5 \\
\hline $7 / 2 / 2018$ & 7 & - & 2 & - & 2 & - \\
\hline $27 / 2 / 2018$ & 43 & 2 & 8 & 3 & 3 & 29 \\
\hline $8 / 3 / 2018$ & 54 & - & 5 & 6 & - & - \\
\hline $12 / 3 / 2018$ & 64 & - & 5 & - & 5 & 6 \\
\hline $5 / 4 / 2018$ & 65 & 14 & 2 & 2 & 2 & - \\
\hline $16 / 4 / 2018$ & 45 & 6 & - & - & 4 & 1 \\
\hline $19 / 4 / 2018$ & 50 & 32 & 5 & 6 & - & 3 \\
\hline $26 / 4 / 2018$ & 54 & 35 & 10 & 2 & 2 & \\
\hline $2 / 5 / 2018$ & 50 & 2 & 6 & - & 8 & \\
\hline $10 / 5 / 2018$ & 1 & 3 & & & 4 & 3 \\
\hline
\end{tabular}

Table 2. Types and populations of mosquito immature stages predators in study locations

\begin{tabular}{|l|r|c|c|c|}
\hline \multicolumn{1}{|c|}{ Predator order } & Family & (A) Pond & (B) Streamlet & (C) Pool \\
\hline Insect ( Hemiptera ) & Corixidae & ++++ & + & ++ \\
\cline { 2 - 5 } & Cieadellidae & - & - & + \\
\hline Insect ( Odonata ) & Corduliidae & - & + & - \\
\cline { 2 - 5 } & Coenagrionidae & - & + & +++ \\
\hline
\end{tabular}




\begin{tabular}{|l|r|r|r|c|}
\hline $\begin{array}{l}\text { Fish } \\
\text { (Cyprinodontiformes ) }\end{array}$ & Poeciliidae & - & - & ++ \\
\hline
\end{tabular}

( - ) no predator

$(+)$ No. of predator is $1-5$

$(++)$ No. of predator is $6-10$

$(+++)$ No. of predator is $11-20$

$(++++)$ No. of predator is $21-30$

\section{The rate of the effect of alcoholic extracts of plants (Apple of Sodom, Lantana, and cloves) on the second instar larvae:}

A study of natural products of plant origin was studied after extracting alcohol for plants (apple of Sodom, lantana and cloves), and an attempt was made to prove their effectiveness in controlling the second and fourth instar larvae of $C x$. Quinquefasciatus and made it a larvicidal pesticide in controlling mosquito larvae at a certain level and not reaching the population explosion, as it was found that clove extract was very effective in all different concentrations $(2.5,5,10$ and $15 \%)$ where the average mortality percentage was 4.00 , which is the highest in the mortality at a concentration of $2.5 \%$. However, it was found that the clove extract reduced the mosquito larvae of the second instar within 6 hours, as it made the mortality $100 \%$. Also, it has been noted that the apple of sodom remains effective in the control and mortality of the instar larvae even after 48 hours and when compared to the extract of lantana where it was for apple of sodom 4 and in the lantana extract 2.67, and the average mortality percentage in apple of sodom and lantana extract at a concentration of $2.5 \%$ was reached 1.47 (Table 3). While in Table (4 and 5) it is shown when increasing the concentration (5 and 10\%) the active substances will be increased, where at a concentration of $5 \%$, the clove extract was increased after 2 hours, however the mosquito larvae were reduced after 4 hours, and the apple of Sodom extract at concentration of 5\% was given the mortality after 2 hours for the second instar larvae. Whereas the apple of Sodom extract reached 2.67, while the lantana was 0.67 , this indicates that the apple of sodom had more effect than the lantana at a concentration (5 and 10\%), where the average mortality for the apple of sodom was (2.27 and 2.67) and for the lanatana 
it was $(1.33,0.93)$. It was noticed that the apple of sodom extended its effect in controlling the second instar larvae after 48 hours, it reached 6.33 while in lantana extract was reached 1.33. In table (6) it was found that lantana extract at concentration of $15 \%$ was more toxic than apple of sodom on second instar larvae of Cx. Quinquefasciatus, where the lantana extract had an average ratio of (3.27) and as for the apple of sodom it was (1.87).

As for the fourth stage larvae, as Table (7 and 8) shows, the clove had a strong effect in reduced mosquito larvae after 2 hours, as the mortality percentage of fourth instar larvae reached 15.17, but the effect of clove extract decreased after 4 hours, reaching 3.08. It was also noticed that the apple of sodom had more effect than the lantana extract. It was found that there was no difference in the mortality even after increasing the concentration where the average mortality percentage was equal in the concentration of 2.5 and $5 \%$, whereas the apple of Sodom had 2.07 but for the lantana was 1.75 .

In this study, it was shown that the alcoholic extract of cloves was required $100 \%$ of the larvae with insecticide activity against the second and fourth instar larvae due to the lethal effect of the clove extract which is the presence of terpenoids in agreement with a study conducted by (Hemalatha $\boldsymbol{e t}$ al. 2015), They found a mortality rate of $100 \%$ in $150 \mathrm{ppm}$, as it revealed the presence of terpenoids, cyanins, flavonoids and glycosides.

Plus, it was found that the alcoholic extract of apple of sodom has an effect on the second and fourth instar larvae. It can be used as insecticide and its effect remains effective even after 48 hours. This was in agreement with a study conducted by (Elimam $\boldsymbol{e t}$ al, 2010), where they suggested extracting an aqueous extract from Calotropis procera leaf extracts as a fungicide that can be used naturally in controlling mosquitoes in Sudan, it is considered environmentally safe, less costly, economical, and practical in application.

Table 3. Effect of $2.5 \%$ alcohol plants extract on $2^{\text {nd }}$ mosquito instar larvae 
INTERNATIONAL JOURNAL OF

FAMILY STUDIES, FOOD SCIENCE AND NUTRITION

HEALTH

ISSN: $2735-5381$

VOLUME 4, ISSUE 1, 2021, 1- 18.

www.egyptfuture.org/ojs/

\begin{tabular}{|c|c|c|c|c|c|c|}
\hline \multirow{2}{*}{ Plant } & \multicolumn{5}{|c|}{ Mortality percent after 2, 4, 6, 24, and 48 hours } & \multirow{2}{*}{ mean } \\
\cline { 2 - 6 } & 2 & 4 & 6 & 24 & 48 & \\
\hline $\begin{array}{c}\text { Apple of } \\
\text { Sodom }\end{array}$ & 1.33 & - & 0.33 & 1.67 & 4.00 & 1.47 \\
\hline Lantana & 1.67 & - & 0.33 & 2.67 & 2.67 & 1.47 \\
\hline clove & 4.00 & 9.00 & 7.00 & - & - & 4.00 \\
\hline LSD 0.05 & \multicolumn{7}{|c|}{1.31} & 0.58 \\
\hline mean & 2.33 & 3.00 & 2.56 & 1.44 & 2.22 & \\
\hline LSD 0.05 & & 0.76 & \\
\hline
\end{tabular}

Table 4. Effect of 5\% alcohol plants extract on $2^{\text {nd }}$ mosquito larvae

\begin{tabular}{|c|c|c|c|c|c|c|}
\hline \multirow[t]{2}{*}{ Plant } & \multicolumn{5}{|c|}{ Mortality percent after $2,4,6,24$, and 48 hours } & \multirow[t]{2}{*}{ mean } \\
\hline & 2 & 4 & 6 & 24 & 48 & \\
\hline
\end{tabular}


INTERNATIONAL JOURNAL OF

FAMILY STUDIES, FOOD SCIENCE AND NUTRITION

HEALTH

ISSN: $2735-5381$

VOLUME 4, ISSUE 1, 2021, 1- 18.

www.egyptfuture.org/ojs/

\begin{tabular}{|c|r|r|r|r|r|r|}
\hline $\begin{array}{c}\text { Apple of } \\
\text { Sodom }\end{array}$ & 2.67 & 1.33 & 1.67 & 2.33 & 3.33 & 2.27 \\
\hline Lantana & 0.67 & 0.33 & 0.67 & 1.67 & 3.33 & 1.33 \\
\hline clove & 16.67 & 3.33 & - & - & - & 4.00 \\
\hline LSD 0.05 & \multicolumn{7}{|c|}{3.73} & 1.67 \\
\cline { 1 - 3 } mean & 6.67 & 1.67 & 0.78 & 1.33 & 2.22 & \\
\cline { 1 - 3 } LSD 0.05 & \multicolumn{7}{|c|}{2.15} & \\
\hline
\end{tabular}

Table 5. Effect of $10 \%$ alcohol plants extract on $2^{\text {nd }}$ mosquito instar larvae

\begin{tabular}{|c|c|c|c|c|c|c|}
\hline \multirow[t]{2}{*}{ Plant } & \multicolumn{5}{|c|}{ Mortality percent after $2,4,6,24$, and 48 hours } & \multirow[t]{2}{*}{ mean } \\
\hline & 2 & 4 & 6 & 24 & 48 & \\
\hline $\begin{array}{r}\text { Apple of } \\
\text { Sodom }\end{array}$ & 1.67 & 1.00 & 0.33 & 4.00 & 6.33 & 2.67 \\
\hline Lantana & 0.33 & 0.67 & - & 2.33 & 1.33 & 0.93 \\
\hline clove & 20.00 & - & - & - & - & 4.00 \\
\hline LSD 0.05 & \multicolumn{5}{|c|}{1.45} & \multirow[t]{3}{*}{0.65} \\
\hline mean & 7.33 & 0.56 & 0.11 & 2.11 & 2.56 & \\
\hline LSD 0.05 & \multicolumn{5}{|c|}{0.84} & \\
\hline
\end{tabular}

Table 6 . Effect of $15 \%$ alcohol plants extract on $2^{\text {nd }}$ mosquito instar larvae 
INTERNATIONAL JOURNAL OF

FAMILY STUDIES, FOOD SCIENCE AND NUTRITION

HEALTH

ISSN: $2735-5381$

VOLUME 4, ISSUE 1, 2021, 1- 18.

www.egyptfuture.org/ojs/

\begin{tabular}{|c|c|c|c|c|c|c|}
\hline \multirow[t]{2}{*}{ Plant } & \multicolumn{5}{|c|}{ Mortality percent after $2,4,6,24$, and 48 hours } & \multirow[t]{2}{*}{ mean } \\
\hline & 2 & 4 & 6 & 24 & 48 & \\
\hline $\begin{array}{r}\text { Apple of } \\
\text { Sodom }\end{array}$ & 1.33 & 0.33 & - & 3.33 & 4.33 & 1.87 \\
\hline Lantana & 1.67 & 0.33 & 0.67 & 3.67 & 10.00 & 3.27 \\
\hline clove & 20.00 & - & - & - & 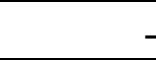 & 4.00 \\
\hline LSD 0.05 & \multicolumn{5}{|c|}{1.02} & \multirow[t]{3}{*}{0.46} \\
\hline mean & 7.67 & 0.22 & 0.22 & 2.33 & 4.78 & \\
\hline LSD 0.05 & \multicolumn{5}{|c|}{0.59} & \\
\hline
\end{tabular}

Table 7. Effect of $2.5 \%$ alcohol plants extract on $4^{\text {th }}$ mosquito instar larvae

\begin{tabular}{|c|c|c|c|c|c|c|}
\hline \multirow[t]{2}{*}{ Plant } & \multicolumn{5}{|c|}{ Mortality percent after $2,4,6,24$, and 48 hours } & \multirow[t]{2}{*}{ mean } \\
\hline & 2 & 4 & 6 & 24 & 48 & \\
\hline $\begin{array}{r}\text { Apple of } \\
\text { Sodom }\end{array}$ & 1.75 & 0.67 & 0.57 & 2.83 & 4.50 & 2.07 \\
\hline Lantana & 1.08 & 0.33 & 0.42 & 2.58 & 4.33 & 1.75 \\
\hline clove & 15.17 & 3.08 & 1.75 & - & - & 4.00 \\
\hline LSD 0.05 & \multicolumn{5}{|c|}{2.15} & \multirow[t]{3}{*}{0.96} \\
\hline mean & 6.00 & 1.36 & 0.92 & 1.81 & 2.94 & \\
\hline LSD 0.05 & \multicolumn{5}{|c|}{1.24} & \\
\hline
\end{tabular}


Table 8. Effect of $5 \%$ alcohol plants extract on $4^{\text {th }}$ mosquito instar larvae

\begin{tabular}{|c|c|c|c|c|c|c|}
\hline \multirow[t]{2}{*}{ Plant } & \multicolumn{5}{|c|}{ Mortality percent after $2,4,6,24$, and 48 hours } & \multirow[t]{2}{*}{ mean } \\
\hline & 2 & 4 & 6 & 24 & 48 & \\
\hline $\begin{array}{r}\text { Apple of } \\
\text { Sodom }\end{array}$ & 1.33 & 1.67 & 1 & 2.33 & 4.33 & 2.13 \\
\hline Lantana & 0.00 & 1 & 0.67 & 1.67 & 4.67 & 1.60 \\
\hline clove & 2 & 1.67 & 1.33 & 5.67 & 2.67 & 2.67 \\
\hline LSD 0.05 & \multicolumn{5}{|c|}{2.15} & \multirow[t]{3}{*}{1.39} \\
\hline mean & 1.11 & 1.44 & 1.00 & 3.22 & 3.89 & \\
\hline LSD 0.05 & \multicolumn{5}{|c|}{1.47} & \\
\hline
\end{tabular}

Table 9. Effect of $10 \%$ alcohol plants extract on $4^{\text {th }}$ mosquito instar larvae

\begin{tabular}{|c|c|c|c|c|c|c|}
\hline \multirow[t]{2}{*}{ Plant } & \multicolumn{5}{|c|}{ Mortality percent after $2,4,6,24$, and 48 hours } & \multirow[t]{2}{*}{ mean } \\
\hline & 2 & 4 & 6 & 24 & 48 & \\
\hline $\begin{array}{r}\text { Apple of } \\
\text { Sodom }\end{array}$ & 1.67 & 3 & 1.33 & 2 & 1 & 3.00 \\
\hline Lantana & 1.33 & 1.33 & 0.33 & 1.67 & 2 & 1.33 \\
\hline clove & 1.67 & 1 & 1.33 & 3.67 & 2.67 & 3.47 \\
\hline LSD 0.05 & \multicolumn{5}{|c|}{0.89} & \multirow[t]{3}{*}{0.91} \\
\hline mean & 1.56 & 1.56 & 0.78 & 2.42 & 1.89 & \\
\hline LSD 0.05 & \multicolumn{5}{|c|}{1.11} & \\
\hline
\end{tabular}


Table 10. Effect of $15 \%$ alcohol plants extract on $4^{\text {th }}$ mosquito instar larvae

\begin{tabular}{|c|c|c|c|c|c|c|}
\hline \multirow[t]{2}{*}{ Plant } & \multicolumn{5}{|c|}{ Mortality percent after $2,4,6,24$, and 48 hours } & \multirow[t]{2}{*}{ mean } \\
\hline & 2 & 4 & 6 & 24 & 48 & \\
\hline $\begin{array}{r}\text { Apple of } \\
\text { Sodom }\end{array}$ & 0.33 & 2.67 & 4 & 5 & 5 & 3.40 \\
\hline Lantana & 0.00 & 0.67 & 1.33 & 1 & 5.67 & 1.73 \\
\hline clove & 13.33 & 2.67 & 1.67 & 2.33 & 0.00 & 4.00 \\
\hline LSD 0.05 & \multicolumn{5}{|c|}{3.33} & \multirow[t]{3}{*}{3.26} \\
\hline mean & 4.56 & 2.00 & 2.33 & 2.78 & 3.56 & \\
\hline LSD 0.05 & \multicolumn{5}{|c|}{4.32} & \\
\hline
\end{tabular}




\section{References}

Achee, N.L., Grieco, J.P., Vatandoost, H., Seixas, G., Pinto, J.and Ching-NG, L 2019. Alternative strategies for mosquito-borne arbovirus control. PLoS Negl Trop Dis 13(1): e0006822. https://doi.org/10.1371/journal.pntd.0006822 .

Abu Al- Hab, J. 1990. Disease vector insects. National Board of Culture, Arts and Etiquette, Kwait. 225 pp.

Ahmed, M.A.I. and C. Vogel. 2020. The function of octopamine receptor agonists stimulating the effects of selected insect growth regulators on Culex quinquefasciatus Say (Diptera: Culicidae) mosquitoes. One Health. 10: 100138.

Ahmed, M.A.I. and A.A. Othman. 2020. Piperonyl butoxide enhances the insecticidal toxicity of nano-formulation of imidacloprid on Culex pipiens (Diptera: Culicidae) mosquito. Vector-Borne and Zoonotic Diseases. 20 (2): 134-142. 
Al-Ghoury, A.A., W.K. El-Hashimi and J. Abul-Hab. 2006. Epidemiology of malaria and predictions of retransmission in Babylon Governorate, Iraq. Eastern Mediterranean Health Journal. 12 (3-4): 270-279.

Brathwaite, D.O., San Martín, J.L., Montoya, R.H., del Diego, J., Zambrano, B. and Dayan, G.H.2012. The history of dengue outbreaks in the Americas. Am J Trop Med Hyg, 87:584-93.

De Bueno, A.F.; Carvalho, G.A.; dos Santos, A.C.; Sosa-Gómez, D.R.; da Silva, D.M. Pesticide selectivity to natural enemies: Challenges and constraints for research and field recommendation. Ciênc. Rural, 47, 1-10.

El-Hadeeti, S.A.K., A.I. Farghal, T.M. Abo-Elmaged, Y.A. Darwish, M.A.K. Nasser. 2017. Influence of certain eco-physiological factors on predation efficiency of Gambusia affinis (Baird and Girard) on Culicine mosquito larvae. J. Phytopathol. Pest Manag. 4 (2): 62-68.

EL Hag E.A., A.H. El Nadi and A.A. Zaitoon, Toxic and growth retarding effect of three plant extracts on Culex pipiens larvae. (Diptera:Culicidae). Phytotherapy Research. 13 (5): 388-392.

Elimam A.M., K.H. Elmi and F.S. Ali. 2010. Efficacy of leaves extract of Calotropis procera Ait (Asclepidaceae) in controlling Anopheles arabiensis and Culex quinquefasciatus. Soudi Journal of Biological Sciences. 16 (2): 95-100.

Elono, A.L.M., M. Liess, and S. Dusquene. 2010. Influence of competing and predatory invertebrate taxa on larval populations of mosquitoes in temporary ponds of wetland areas in Germany. J. Vector Ecol. 35: 419-427. 
Hasty, J.M. and P. Yang. 2011. Survey of immature mosquito predators from Taro fields on the island of Kauai, Hawaii. Proceedings of the Hawaiian EntomologIcal Society. 43: 13-22.

Hemalatha, P., D. Elumalai, A. Janaki, M. Babu, K. Velu, K. Velayutham and P. K. Kaleena. 2015. Larvicidal activity of Lantana camara aculeate against three important mosquito species. J. Entomol Zool stud. 3(1):174-181.

Mittal, P. and S.k. Subbarao. 2003. Prospects of using herbal product in the control of mosquito vectors. ICMR BULLETIN. 33(1).

Mogi, M. 2007. Insects and other invertebrate predators. 2007. Journal of the American Mosquito Control Association. 23 (sp2): 93-109.

Shaalan, E.A., D.V. Canyon, R. Muller, M.W. F. Younes, H. Abdelwahab and A. H. Mansour. 2007. A mosquito predator survey in Townsville, Australia, and an assessment of Diplonychus sp. And Anisops sp. predatorial capacity against Culex annulirostris mosquito immatures. J. Vector Ecol. 32: 16 -21.

Sharma, N., J.S. Qadry, B. Subramanium, T. Verghese, S.J. Rahman, S.K. Sharma and S. Jalees. 1998. Larvicidal Activity of Gliricidia sppium against mosquito Larvae of Anopheles stephansi, Aedes aegypti and Culex quinquefas ciatus. pham. Bio. 36: 3-7.

Sosan, M.B., F.B. Adewoyin and C.O. Adewunmi. 2001. Larvicidal properties of three indigenous plant Oils on the mosquito Aedes aegypti. Nig. J. Nat. Prod. And Med. 5:30-33.

World Health Organization (WHO). 1970. Insecticide Resistance and Vector 17th Report of WHO Expert Committee on Insecticides WHO tech Report, Ser No. 443. 
INTERNATIONAL JOURNAL OF

FAMILY STUDIES, FOOD SCIENCE AND NUTRITION

HEALTH

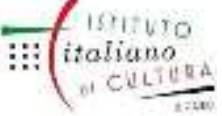

ISSN: 2735-5381

VOLUME 4, ISSUE 1, 2021, 1-18.

www.egyptfuture.org/ojs/

Received: April 2021

Accepted: June 2021 